\title{
COMPOSIÇÃO CORPORAL E ALIMENTAR DO MATRINXÃ, Brycon cephalus (Günther, 1869), NA AMAZÔNIA CENTRAL ${ }^{1}$
}

\author{
Emer Gloria PIZANGO-PAIMA ${ }^{2}$, Manoel PEREIRA-FILHO ${ }^{3}$, \\ Maria Inêz de OLIVEIRA-PEREIRA ${ }^{3}$
}

RESUMO - Foram estudados a dieta, a composição corporal e o valor de energia bruta do conteúdo estomacal, filé e figado, bem como alguns frutos e sementes que fazem parte da dieta do matrinxã, relacionando-se estes parâmetros com as flutuações do nivel da água durante um ciclo anual. Observou-se que a espécie se alimenta de sementes, frutos, flores, restos de vegetais e insetos, apresentando hábito alimentar onivoro. Estômagos vazios foram freqüentes $(68,5 \%)$ nos diferentes períodos hidrológicos. As análises proximais e valor da energia bruta do filé e fígado dos peixes analisados não apresentaram diferenças significativas entre os sexos $(P>0,05)$. No entanto, observou-se diferenças entre os periodos de águas baixas e altas. As médias das composições centesimais e os valores de energia bruta do conteúdo estomacal, expressos com base na matéria seca revelaram, na enchente, um baixo teor de proteina $(8,9 \%)$ e cinza $(1,3 \%)$, alto valor de lipídios $(70,2 \%)$ e energia $(775 \mathrm{Kcal} \mathrm{EB} / 100 \mathrm{~g})$. Na seca, o teor de proteina $(24,9 \%)$ e cinza $(6,3 \%)$ foram maiores, porém os teores de lipídios $(13,2 \%)$ e de energia $(416,9 \mathrm{Kcal} \mathrm{EB}$ $100 \mathrm{~g}$ ) foram mais baixos que na cheia. Foi verificado abundante depósito de gordura cavitária o ano todo, diminuindo em janeiro, mês em que o matrinxã realiza a desova

Palavras-chave: Brycon cephalus, alimentação natural, indice alimentar, variação sazonal, valor nutritivo.

Body Composition and Food of the Matrinxã, Brycon cephalus (Günther, 1869) (Characiformes, Characidae) from Central Amazonia.

ABSTRACT - In the present paper were studied the diet, the body composition, and the gross energy value of the stomach contents, fillet and liver, as well as some fruits and seeds that are part of the natural diet of the matrinxã, linking these parameters with the river's annual water level flutuations. The matrinxã was observed to feed on seeds, fruits, flowers, remains of vegetables and insects, presenting an omnivorous feeding habit. Empty stomaches were frequent $(68.5 \%)$ in the different hydrologic periods. The proximal analysis and gross energy value of the fillet and liver of the analyzed fish did not present significant differences between the sexes $(\mathrm{P}>0.05)$. However, differences between the periods of low and high waters were observed. Median proximal composition and gross energy values of the stomach contents, expressed as dry matter revealed a low content of protein (8.9\%) and ash (1.3\%), and high value of lipids $(70.2 \%)$ and energy $(775 \mathrm{Kcal} \mathrm{EB} / 100 \mathrm{~g})$ during high water. During the low water period, protein $(24.9 \%)$ and ash values $(6.3 \%)$ were high, and lipids (13.2\%) and energy values $(416.9 \mathrm{Kcal} \mathrm{EB} 100 \mathrm{~g})$ were low. Abundant deposits of body fat were verified the whole year, decreasing during the spawning period in January.

Key-words: Brycon cephalus, natural food, alimentary index, seasonal variation, nutritive value.

\section{INTRODUÇÃO}

As espécies do gênero Brycon são distribuídas amplamente na América Central e do Sul e o gênero é considerado um dos maiores dentro dos Characiformes neotropicais. O matrinxã, Brycon cephalus (Günther, 1869), é uma espécie que restringe-se à bacia Amazônica (Howes, 1982).

\footnotetext{
${ }^{1}$ Parte da dissertação de mestrado do primeiro autor.

${ }^{2}$ Bolsista do CNPq.Universidad Nacional de la Amazonia Peruana. Apto. 326, Iquitos, Perú.

${ }^{3}$ CPAQ-INPA, CP 478, Manaus-AM, E-Mail: pmanoel@inpa.gov.br
} 
São escassos os estudos sobre a biologia desta espécie em ambiente natural. Borges (1986) estudou os aspectos bioecológicos; ZaniboniFilho \& Resende (1988) os aspectos reprodutivos e Villacorta-Correa (1987) o crescimento.

As informações sobre os itens alimentares encontrados no conteúdo estomacal de espécies do gênero Brycon revelaram a presença de frutos, sementes, folhas, insetos, sendo por isto classificadas como onívoras (Knoppel, 1970; Goulding, 1980; Cánepa, 1982; Borges, 1986). Porém pouco se conhece sobre a qualidade nutricional e valor energético dos itens alimentares desta espécie.

Tendo em vista a grande potencialidade do matrinxã para a piscicultura e a ausência de informações sobre o valor nutritivo dos seus itens alimentares, o objetivo deste trabalho foi identificar os itens que compõem sua dieta no ambiente natural, analisar a composição centesimal e conteúdo energético destes itens, e relacioná-la com a composição do filé e fígado ao longo de um ciclo anual.

\section{MATERIAIS E MÉTODOS}

Foram utilizados um total de 225 exemplares de matrinxã, obtidos da pesca comercial e de excursões periódicas ao rio Negro e afluentes, entre maio de 1995 e abril de 1996. As análises da composição centesimal e do teor energético das amostras foram realizadas no Laboratório de Nutrição de Peixes, da Coordenação de Pesquisas em Aqüicultura-CPAQ, do Instituto Nacional de Pesquisas da
Amazônia INPA, Manaus-AM.

Após a coleta os peixes foram conservados em gelo e transportados até o laboratório onde foram agrupados em lotes de cinco individuos e registrados os comprimentos padrão $\left(\mathrm{L}_{\mathrm{p}}\right)$ e furcal $\left(\mathrm{L}_{\mathrm{F}}\right)$, em $\mathrm{mm}$. O trato digestivo foi removido, obtido o peso do conteúdo estomacal, identificados seus constituintes com uso do método da frequência de ocorrência, e determinada sua composição químicocentesimal.

Foi retirada uma porção do filé da região dorsal direita dos peixes, os quais foram agrupados por sexo, homogeneizados em liqüidificador e conservados em congelador para posterior análise.

Baseando-se nos resultados de Cánepa (1982), Borges (1986) e informações dos pescadores sobre os itens alimentares do matrinxã, foram tambem coletados frutos e sementes consumidos por esta espécie, os quais foram colhidos verdes, maduros, e em alguns casos junto a suas inflorescências. Todas as amostras foram colocadas em sacos plásticos e transportadas ao laboratório em caixas de isopor com gelo, onde foram estocados em congelador, para posteriores análises da composição centesimal. As análises realizadas com base nos métodos da A.O.A.C. (1995) foram:

- Umidade, determinada considerando-se a perda de peso durante a pré-secagem (liofilização), mais o peso perdido quando alíquotas do material foram submetidos a temperatura de 
$105^{\circ} \mathrm{C}$ até peso constante;

- Proteína bruta (método de micro-Kjehldal) determinando-se o teor de nitrogênio total, que foi multiplicado pelo fator 6,25 ;

- Cinza, determinada por queima em mufla a $550{ }^{\circ} \mathrm{C}$ durante 3 horas;

- Gordura, por extração continua com éter de petróleo em extrator de Soxleth;

- Fibra bruta, por digestão ácidobasica (método de Weende);

- Extrativos não nitrogenados, por diferença.

- A energia bruta foi obtida por queima em bomba calorimétrica adiabática.

Todos os resultados de composição centesimal obtidos neste trabalho são expressos com base em $100 \%$ da matéria seca (MS).

\section{RESULTADOS}

A Tabela 1 apresenta os itens alimentares de origem vegetal encontrados no conteủdo estomacal do matrinxã. Destes, mais da metade eram representados por sementes $(51,4 \%)$ das quais $19 \%$ pertenciam a Pouteria gonphiifolia, enquanto $21 \%$ não puderam ser identificadas por estarem excessivamente trituradas. $\mathrm{O}$ segundo item vegetal em importância foram as flores, com $26 \%$ do conteúdo estomacal, representadas por duas espécies identificadas (total de $16,7 \%$ ), e flores que não puderam ser identificadas $(9,5 \%)$. Entre os frutos, Ficus sp. foi o mais importante, contribuindo com $9,5 \%$ do total.

Em todos os períodos hidrológicos houve uma predominância de estômagos vazios ou com pouco conteúdo estomacal (grau de repleção de até $10 \%$ ), somente 10 exemplares apresentaram estômagos com mais de $50 \%$ de grau de repleção (Fig. 1).

De acordo com os diferentes níveis da água dos rios foram

Tabela 1. Freqüência de ocorrência de frutos, sementes e flores encontrados no conteúdo estomacal do matrinxã, Brycon cephalus (Günther, 1869), em função da flutuação do nível do rio, capturados ao longo de um ciclo hidrológico nos rios Negro e Solimões.

\begin{tabular}{cllc}
\hline \multicolumn{1}{c}{ Itens } & \multicolumn{1}{c}{ Famílias } & \multicolumn{1}{c}{ Espécies } & $\%$ de Ocorrência \\
\hline Frutos & Anonaceae & Dugetia sp * & $2,4 \%$ \\
& Maraceae & Ficus sp. & $9,5 \%$ \\
& & Cecropia sp. & $2,4 \%$ \\
\multirow{5}{*}{ Sementes } & Năo identificada & & $7,1 \%$ \\
& Chartaceae * & & $4,8 \%$ \\
& Poaceae & & $4,8 \%$ \\
& Leguminosae & & $2,4 \%$ \\
& Sapotaceae & Pouteria gonphiifolia* & $19,0 \%$ \\
\multirow{5}{*}{ Flores } & Não identificada & & $21,4 \%$ \\
& Bignonaceae & Tabebuia barbata & $4,8 \%$ \\
& Lecythidaceae & Eschweilera sp. * & $11,9 \%$ \\
& Não identificada & & $9,5 \%$ \\
\hline
\end{tabular}

${ }^{*}=$ Identificados no presente estudo e năo encontradas na literatura. 


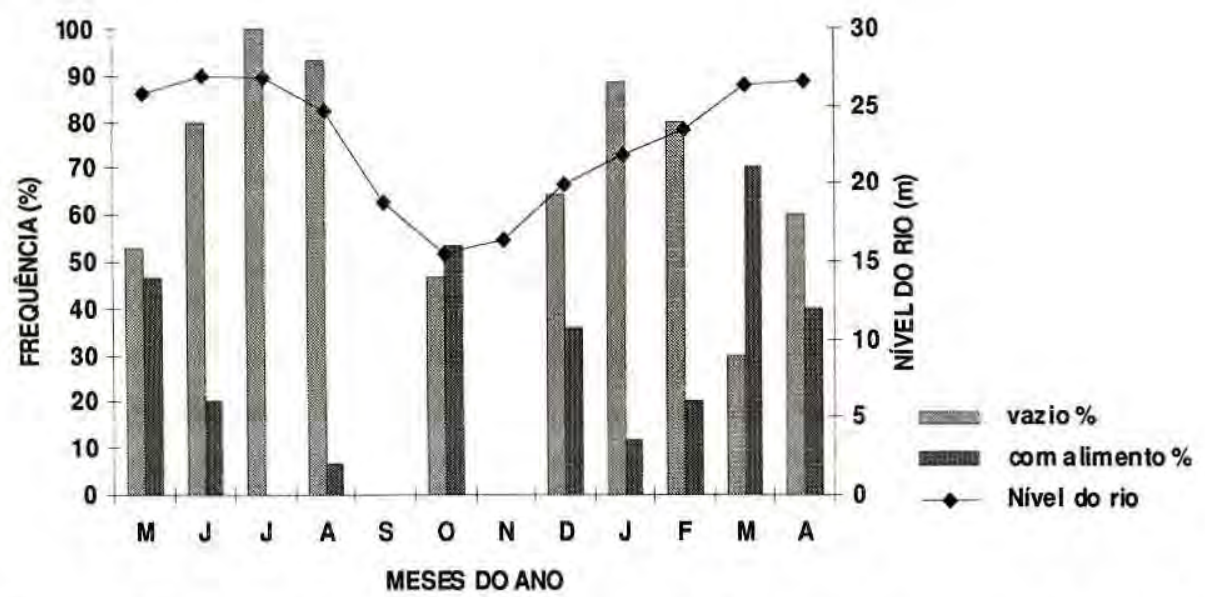

Figura 1. Frequência de ocorrência de estômagos cheios e vazios, ao longo de um ciclo hidrológico, de Brycon cephalus (Günther,1869), capturados nos rios Negro e Solimões.

observadas variações na composição do conteúdo estomacal do matrinxã, tanto no que se refere a itens de origem vegetal quanto a itens de origem animal. Entre os itens de origem vegetal, na enchente e cheia predominaram as sementes $(35,2 \mathrm{e}$ 35,7 respectivamente) seguidas por restos vegetais $(22,2$ e 28,6$)$. Na seca os itens de origem vegetal mais importantes foram restos vegetais $(37,5)$ e plantas herbáceas $(75,0)$.

Quanto aos itens de origem animal, insetos adultos $(44,4)$ restos de peixes $(31,5)$ e de insetos $(25,9)$ foram predominantes na enchente. Na cheia predominaram insetos adultos $(42,9) \mathrm{e}$ restos de peixe $(21,4)$, enquanto insetos imaturos e restos de insetos deram valores iguais $(14,3)$. Na seca observou-se um predominio absoluto de restos de peixe no conteúdo estomacal dos animais estudados.

Como a maioria dos estômagos dos peixes estava vazio $(65,8 \%)$ e os que apresentaram alimento tinham grau médio de repleção de $10 \%$, somente foi possivel realizar as análises da composição centesimal em 5 amostras no período de seca e 10 no periodo de enchente. Observou-se que o conteúdo estomacal dos animais amostrados no período de seca era mais rico em proteina $(24,9 \%)$ e minerais $(6,3 \%)$ e mais pobres em extrato etéreo $(13,25 \%)$ e energia $(416,0 \mathrm{Kcal} \mathrm{EB} / 100 \mathrm{~g})$ que no período da cheia $(8,9 \%, 70,2 \%, 1,3 \%$ e 775 Kcal EB/100g respectivamente) (Tab.3)

As análises bromatológicas dos principais frutos e sementes que, segundo a literatura (Goulding, 1980; Cánepa, 1982; Borges,1986) o matrinxã consome na natureza, mostraram que as sementes em média são mais ricas em nutrientes e energia que os frutos, e apresentam menor teor médio de umidade. No entanto foram 
Tabela 2. Itens encontrados no conteúdo estomacal do matrinxã, Brycon cephalus (Günther, 1869), capturados ao longo de um ciclo hidrológico nos rios Negro e Solimões.

\begin{tabular}{|c|c|c|c|c|c|c|}
\hline \multirow{2}{*}{$\begin{array}{l}\text { Periodos } \\
\text { Itens }\end{array}$} & \multirow[b]{2}{*}{$\mathrm{n}$} & \multicolumn{2}{|c|}{ Enchente } & \multirow{2}{*}{$\begin{array}{c}\text { Cheia } \\
\text { Fi }\end{array}$} & \multicolumn{2}{|c|}{ Seca } \\
\hline & & $\mathrm{Fi}$ & $\mathrm{n}$ & & $\mathrm{N}$ & $\mathrm{Fi}$ \\
\hline Frutos & 3 & 5,60 & 1 & 7,1 & & \\
\hline Sementes & 19 & 35,20 & 5 & 35,7 & & \\
\hline Flores & 5 & 9,30 & & & 3 & 37,500 \\
\hline Rest. vegetais & 12 & 22,20 & 4 & 28,6 & 6 & 75,000 \\
\hline Plantas herbac. & 1 & 1,90 & & & & \\
\hline \multicolumn{7}{|l|}{ Insetos: } \\
\hline Adultos & 24 & 44,40 & 6 & 42,9 & & \\
\hline Imaturos & 5 & 9,30 & 2 & 14,3 & & \\
\hline Restos & 14 & 25,90 & 2 & 14,3 & & \\
\hline Aranhas & 3 & 5,60 & 1 & 7,1 & & \\
\hline Anelidos & 2 & 3,70 & & & & \\
\hline Restos de peixes & 17 & 31,50 & 3 & 21,4 & 2 & 38,000 \\
\hline Estôm. Examin & 135 & & 60 & & 15 & \\
\hline Estôm. com alimen & 54 & & 14 & & 8 & \\
\hline
\end{tabular}

Tabela 3. Composição centesimal (\% da MS) e valor energético do conteúdo estomacal do matrinxã, Brycon cephalus (Günther, 1869), capturados ao longo de um ciclo hidrológico nos rios Negro e Solimões.

\begin{tabular}{lccccc}
\hline Periodos & $\mathrm{n}$ & $\mathrm{PB}$ & $\mathrm{EE}$ & $\mathrm{MM}$ & $\mathrm{Kcal}$ EB / 100g \\
\hline Enchente & 10 & 8,9 & 70,2 & 1,3 & 775,0 \\
Seca & 5 & 24,9 & 13,2 & 6,3 & 416,9
\end{tabular}

$\mathrm{N}=\mathrm{n}^{\circ}$ de animais amostrados; $\mathrm{PB}=$ proteina bruta; $\mathrm{EE}=$ extrato etéreo; $\mathrm{MM}=$ matéria mineral.

observados frutos com bons teores de nutrientes, com destaque para Tabebuia barbata que apresentou $14,9 \%$ de proteina, $24,3 \%$ de extrato

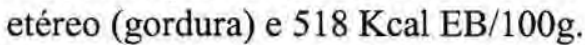
Entre as sementes, as duas espécies de Hevea (H. spruceana e H. brasiliensis) foram as mais ricas em nutrientes, apresentando níveis de proteina de 16,7 e $16,3 \%$; extrato etéreo, 43,7 e $40,1 \%$; e energia bruta, 595,7 e 662,4
Kcal EB/100g (Tab. 4)

Foi determinada a composição centesimal e energia bruta do filé e do fígado de todos os animais coletados durante o experimento, em um total de 137 fêmeas e 88 machos, os quais foram analisados separadamente. Foram obtidos resultados heterogêneos para todos os parâmetros determinados. O teor de proteina do filé variou de um minimo de $53 \%$ da 
Tabela 4. Composição centesimal (\% da MS) e valor de energia bruta(Kcal/100g MS) dos frutos e sementes consumidos por matrinxã, Brycon cephalus (Günther, 1869), coletados ao longo de um ciclo hidrológico nos rios Negro e Solimões.

\begin{tabular}{|c|c|c|c|c|c|c|c|}
\hline ESPÉCIE & UM & PB & EE & ENN & FB & MM & $E B$ \\
\hline \multicolumn{8}{|l|}{ FRUTOS } \\
\hline Astrocaryum jauari & 46,60 & 5,10 & 11,00 & 45,60 & 32,50 & 2,40 & 486,20 \\
\hline Bactris marajá & 54,40 & 6,50 & 10,70 & 48,90 & 27,10 & 3,00 & 473,90 \\
\hline Bactris SP. & 77,50 & 10,90 & 4,30 & 47,60 & 21,00 & 4,60 & 440,10 \\
\hline Cecropia latiloba & 75,00 & 10,70 & 10,50 & 39,60 & 28,50 & 4,20 & 487,90 \\
\hline Calyptranthes ruiziana & $\underline{91.90}$ & 6,20 & 3,50 & $\underline{77.40}$ & 4,50 & 1,80 & 385,20 \\
\hline Crataeva benthamii & 63,20 & 8,60 & 6,10 & 45,50 & 31,40 & $\underline{5.30}$ & 437.70 \\
\hline Couroupita guianensis & 84,40 & 6,30 & 10,00 & 49,20 & 13,00 & 4,20 & 399,30 \\
\hline Ficus $\mathrm{sp}$. & 81,90 & 5,50 & 7.80 & 58,20 & 18,40 & 4,50 & 429,70 \\
\hline Genipa cf. Americana & 69,70 & 2,70 & 4,50 & 69,60 & 11,00 & 3,50 & 427,40 \\
\hline Mabea caudata & 38,50 & 9,60 & 23,80 & 44,80 & 16,30 & 2,70 & 517,39 \\
\hline Mouriri sp. & 85,40 & 4,70 & 4,40 & 47,80 & 33,00 & 3,20 & 422,80 \\
\hline Myrciaria dubia & 91,70 & 3,90 & 7,20 & 55,50 & 20,40 & 1,90 & 382,40 \\
\hline Nectandra sp. & 80,00 & 7,50 & 18,10 & 54,50 & 9,60 & 2,40 & 529,10 \\
\hline Sloanea sp. & 62,20 & 8,60 & 31,80 & 30,10 & 19,20 & 2,40 & $\underline{567.20}$ \\
\hline Tabebuia barbata & 54,90 & 14.90 & $\underline{24,30}$ & 43,50 & 8,60 & 2,20 & 518,30 \\
\hline Média & 70,49 & 7,45 & 11,87 & 50,52 & 19,63 & 3,22 & 460,31 \\
\hline \multicolumn{8}{|l|}{ SEMENTES } \\
\hline Campsiandra comosa & 61,40 & 5,50 & 5,70 & 74,40 & 4,20 & 1,10 & 410,60 \\
\hline Eschweilera sp. & 59,20 & 5,50 & 2,90 & $\underline{79.50}$ & 1,30 & 1,70 & 384,10 \\
\hline Hevea spruceana & 58,30 & 16.70 & $\underline{43.70}$ & 20,90 & 4,20 & 3,40 & 595,70 \\
\hline Hevea brasiliensis & 38,40 & 16.30 & $\underline{40.10}$ & 30,80 & 3,70 & 3,30 & $\underline{662.40}$ \\
\hline Macrolobium acaciifolia & 59,20 & 10,80 & 1,30 & 76,80 & 1,90 & 3,80 & 419,90 \\
\hline Oryza glumaepatula & - & 6,90 & 3,20 & 51,70 & 19,10 & 6,90 & 373,30 \\
\hline Poutria sp. & 78,30 & 5,30 & 11,50 & 48,70 & $\underline{24.90}$ & 3,00 & 462,40 \\
\hline Pseudoxandra polyheba & $\underline{89.90}$ & 6,10 & 9,10 & 49,40 & $\underline{24.20}$ & 3,10 & 421,80 \\
\hline Piranhea trifoliata & 11,10 & 13,70 & 40,70 & 28,00 & 9,80 & 3,20 & 635,40 \\
\hline Média & 56,98 & 9,64 & 17.58 & 51,13 & 10,37 & 3,28 & 485.07 \\
\hline
\end{tabular}

matéria seca, em maio a $73 \%$ em fevereiro. Observou-se uma relação inversa entre os teores de proteína e de extrato etéreo no músculo dos peixes. Os teores de proteina foram mais elevados no músculo dos peixes (média de $63 \%$ da matéria seca) que no figado (média de $42 \%$ ). No entanto os teores de extrato etéreo foram mais elevados no fígado $(33,6 \%)$ que no músculo $(21,6 \%)$, enquanto os valores médios de energia foram bastante próximos, respectivamente 578,8 e $579,8 \mathrm{Kcal} / \mathrm{EB} / 100 \mathrm{~g}$ (Tab. 5).

\section{DISCUSSÃO}

Os resultados obtidos neste estudo revelam uma alta percentagem de estômagos vazios $(65,8 \%)$, com maior frequência na enchente e cheia. Segundo Zaniboni-Filho (1985) durante este periodo os peixes 
Tabela 5. Médias mensais da composição centesimal (\% MS) e teor de energia (EB Kcal $/ 100 \mathrm{~g}$ MS) do filé e figado de matrinxã, Brycon cephalus (Günther, 1869), coletados ao longo de um ciclo hidrológico nos rios Negro e Solimões.

\begin{tabular}{lccccccccccc}
\hline \multicolumn{1}{c}{ Meses } & $n$ & \multicolumn{2}{c}{$\mathrm{PB}$} & \multicolumn{2}{c}{$\mathrm{EE}$} & \multicolumn{2}{c}{$M$} & \multicolumn{2}{c}{$E N N$} & \multicolumn{2}{c}{ EB } \\
\hline & & Filé & figado & filé & Figado & filé & Figado & filé & figado & filé & figado \\
\hline Maio & 15 & 53,00 & 42,37 & 31,20 & 26,60 & 3,90 & 4,30 & 6,50 & 19,03 & 677,0 & 574,9 \\
junho & 30 & 57,00 & 36,99 & 25,30 & 43,86 & 4,30 & 4,51 & 10,30 & 8,18 & 613,3 & 637,8 \\
julho & 15 & 57,10 & 31,90 & 27,70 & 36,67 & 4,30 & 3,17 & 4,30 & 22,08 & 609,3 & 594,7 \\
agosto & 15 & 68,30 & 42,02 & 15,80 & 23,58 & 5,00 & 5,72 & 7,70 & 21,08 & 532,6 & 527,0 \\
outobro & 15 & 70,20 & 39,00 & 15,40 & 43,28 & 4,90 & 6,60 & 1,50 & 2,60 & 534,9 & 640,2 \\
dezembr- & 30 & 63,60 & 44,36 & 20,20 & 28,92 & 4,60 & 4,80 & 3,90 & 13,99 & 552,1 & 575,8 \\
janeiro & 15 & 68,50 & 47,62 & 12,80 & 22,73 & 5,50 & 7,23 & 8,50 & 10,63 & 524,8 & 619,3 \\
fevereiro & 30 & 73,00 & 52,64 & 11,40 & 23,72 & 5,50 & 6,06 & 4,70 & 6,21 & 545,7 & 566,1 \\
Março & 30 & 62,40 & 41,92 & 23,10 & 31,47 & 4,60 & 4,40 & 1,10 & 13,43 & 571,2 & 566,5 \\
Abril & 30 & 58,70 & 42,92 & 29,50 & 38,77 & 4,20 & 4,18 & 1,50 & 8,80 & 634,3 & 586,1 \\
\hline Média & & 63,00 & 42,00 & 21,60 & 33,60 & 4,60 & 5,00 & 4,70 & 12,00 & 578,8 & 579,8 \\
\pm sd & & 6,8 & 6,0 & 7,4 & 9,8 & 4,0 & 1,31 & 4,0 & 7,0 & 51,2 & 44,1 \\
\hline
\end{tabular}

$\mathrm{N}=\mathrm{n}^{2}$ de animais amostrados $; \mathrm{PB}=$ Proteína Bruta; $\mathrm{EE}=$ Extrato Etéreo; $\mathrm{MM}=$ Material Mineral; $\mathrm{ENN}=$ Extrativo não nitrogenado; $\mathrm{FB}=$ Fibra Bruta; $\mathrm{EB}=$ Energia Bruta; $\mathrm{Sd}=$ desvio padrăo.

encontram-se realizando as migrações de baixada do peixe gordo e de reprodução, o que explicaria a não alimentação durante estes períodos.

Nas amostras de estômagos com alimento $(34,2 \%)$ verificou-se a preferência alimentar do matrinxã por insetos adultos, sementes e restos de peixes, especialmente na enchente $\mathrm{e}$ cheia, encontrando-se também insetos, restos de peixes (escamas e visceras) e restos vegetais (podostemaceas e outros). A ocorrência destes itens variou ao longo do ano de acordo com a flutuação do nivel da água.

A oferta alimentar está relacionada às oscilações do nível da água, existindo uma sazonalidade na dieta do matrinxã. Foi verificado neste estudo que, durante a enchente-cheia e seca, o item predominante foi de origem vegetal, predominando as sementes e durante a seca os estômagos continham principalmente flores. A presença deste item nos estômagos, durante a seca e cheia também foi registrada por Borges (1986), enquanto que Goulding (1980) encontrou restos de insetos como o item predominante no período da seca.

A presença do item flores no período da seca (outubro) se deve ao fato de que a maioria das árvores do rio Negro florescem quando a água começa a baixar (Revilla-Cardenas, 1981) e, ante a ausência de outra fonte alimentar, o matrinxã se alimenta do item disponível no ambiente. Assim, esta espécie poderia ser considerada oportunista, conforme citado por Santos (1990) para as espécies do gênero Brycon e serrasalmideos. 
Com relação ao item insetos, espécimens da ordem Hymenoptera foram dominantes no período da enchente, principalmente individuos da família Formicidae, aparecendo também a família Apidae, mas com pouca frequência. Resultados semelhantes foram registrados por Borges (1986) para três espécies de Brycon, porém este item foi predominante no periodo da seca. Santos (1990) observou que Serrasalmus rhombeus (Linnaeus, 1766), espécie quase exclusivamente piscívora, pode aproveitar bem as formigas e cupins no rio Jamari.

Também foi verificada a existência de uma substituição dos diferentes grupos e estádios de desenvolvimento dos insetos no que se refere à freqüência de ocorrência, de acordo com o período hidrológico e local de coleta. Assim, as ordens Hemiptera, Lepidoptera (estágios larvais) foram mais frequentes na cheia, enquanto na enchente as mais frequentes foram Hymenoptera e Ortoptera. As outras ordens, Coleoptera, Tricoptera, Homoptera, Isoptera e Ephemeroptera ocorreram esporadicamente durante ambos períodos. Apesar de frutos e sementes constituírem o item predominante na dieta do matrinxã, acreditamos que os insetos, devido ao número encontrado no presente trabalho, especialmente os de origem alóctone, desempenham um papel importante na dieta da espécie, cuja disponibilidade estả intimamente ligada à inundação da floresta.

Dos itens vegetais encontrados no estômago do matrinxã, somente seis espécies puderam ser identificadas, devido à pouca quantidade de alimento ingerido pela maioria dos peixes e pelo estado adiantado de digestão. De acordo com informações da literatura, 23 famílias e 61 espécies de frutos e sementes foram registradas formando parte da dieta do matrinxã, (Goulding,1980; Cánepa,1982 e Borges,1986). Apesar de ter sido encontrada apenas seis espécies de frutos e sementes nos estômagos dos peixes, muitos daqueles citados pela literatura foram encontrados na floresta, perto dos locais de coleta dos peixes, podendo, portanto, ser potencialmente ingeridos por esta espécie. Por este motivo, baseados nas informações da literatura e coleta de frutos nos locais de captura do matrinxã, foram realizadas análises da composição centesimal de 24 frutos e sementes com a finalidade de se conhecer o aporte nutricional destes itens. Estas análises revelaram que os níveis de proteina e cinza existente nos frutos e sementes são baixos. Estes alimentos, porém, são relativamente altos em lipidios e carboidratos, principalmente as sementes, fornecendo altos teores de energia bruta.

De acordo com os resultados obtidos das análises do conteúdo estomacal do matrinxã, o maior teor protéico foi obtido durante o periodo da seca: $24,9 \%$ na MS. Se comparamos estes resultados com os itens encontrados nos estômagos, podemos observar que neste periodo os itens predominantes foram flores, restos vegetais e restos de peixes em menor proporção. Como o aporte 
protéico de frutos e sementes é baixo, acreditamos que a proteína encontrada tenha sido fornecida pelos restos de peixes encontrados no conteúdo estomacal e pelos insetos que poderiam estar digeridos.

O elevado teor de lipídios (70\%) do conteúdo estomacal no período da enchente, poderia estar relacionado à ingestão de sementes ricas em lipídios durante as amostragens. $\mathrm{O}$ baixo valor de material mineral (1,3\%) na enchente reflete a alimentação predominantemente vegetal e os maiores valores $(6,3 \%)$ na seca, são devidos à presença de alimento de origem animal, como restos de peixes.

A energia bruta do conteúdo estomacal foi mais elevada durante $o$ período de enchente. Isto está relacionado com a disponibilidade de alimento de origem vegetal com elevada concentração de lipídios e carboidratos existentes nesta época. Silva (1997) trabalhando com Colossoma macropomum (Cuvier, 1818), observou valores baixos de proteína no conteúdo estomacal na enchente e cheia, quando são mais disponiveis os frutos e sementes e os maiores valores de proteina foram observados durante a seca, quando os peixes consumiram zooplâncton. Os resultados deste autor concordam com aqueles encontrados neste estudo. Portanto, poderíamos sugerir que este comportamento alimentar é comum aos peixes onívoros que habitam as florestas inundadas, onde existe uma sazonalidade na alimentação.

Os resultados das análises da composição corporal do matrinxã indicam a existência de uma relação entre a composição centesimal da dieta e aquela do filé. Estes resultados concordam com os resultados encontrados por Roubach (1991) que constatou uma relação entre a composição do alimento ingerido (frutos e sementes), e aquela do corpo do peixe, predominando a maior quantidade de lipídios em peixes que consumiram alimento mais energéticos.

De acordo com os resultados deste trabalho, o matrinxã se alimenta pouco durante a vazante e seca, porém o teor de proteína do filé é alto e de lipidios baixo neste período. Isto ocorre porque durante o período de menor disponibilidade de alimento a espécie utiliza primeiro suas reservas de lipídio antes de utilizar a proteina. Zamal \& Ollevier (1995) trabalhando com Clarias gariepinus (Burchell, 1822), observaram que peixes após 66 dias sem alimentação tiveram rápido decréscimo do nível de lipídio e a proteina do músculo significativamente diminuida. Isto indica que, no período de falta de alimento, primeiro são utilizadas as reservas lipidicas para fornecimento de energia, e que após um tempo prolongado de jejum o peixe começa a metabolizar a proteína corporal.

Embora na época da seca a alimentação baseou-se principalmente em flores e restos vegetais, os valores de carboidratos foram muito baixos, o que significa que a presença deste item tenha sido ocasional, na ausência de outro tipo de alimento. A alimentação 
neste periodo porém é constituía principalmente por organismos animais, de acordo com Borges (1986 ), Cánepa (1982) e Goulding (1980), o que pode refletir em teores elevados de proteína.

Os teores de cinza no filé foram os que menos variação apresentaram com as flutuações do nivel das água. No entanto, foram encontrados valores mais elevados durante a seca e enchente. Nesta época os peixes estão com menor teor de gordura corporal, o que eleva relativamente os valores dos outros itens de sua composição .

A energia bruta encontrada no filé do matrinxã teve valores mais elevados durante a cheia, o que é explicável pela maior disponibilidade de frutos e sementes na sua alimentação. Nesta época, grande parte da energia excedente, após suprir os processos de manutenção e crescimento, é acumulada em forma de gordura cavitária e reservas lipídicas corporais.

Wootton (1979) afirmou que muitas espécies de peixe permanecem longos periodos sem comer e que alguns não comem, durante períodos especificos de seu ciclo de vida. A aquisição de alimento é necessária para construir a reserva metabólica para tais períodos. Além da capacidade para mudar sua dieta, os peixes migradores da Amazônia têm estratégias para passar os períodos de baixa oferta alimentar através do consumo das reservas acumuladas em forma de gordura no músculo, figado e/ou cavidade abdominal. A maioria das espécies se alimentam e acumulam gordura durante o periodo de enchente/cheia. Durante a seca, o alimento se torna escasso e as espécies metabolizam as reservas acumuladas. Esta época coincide com o amadurecimento das gônadas e desova (Junk, 1985).

As análises da composição centesimal realizadas no fígado revelam níveis de proteína semelhantes aos encontrados no filé. Houve, porém, diminuição dos valores de lipidios durante a seca. Valores mínimos foram registrados no início da enchente, em janeiro e fevereiro, o que pode indicar que os peixes direcionam estes nutrientes para o desenvolvimento das gônadas. Resultados similares foram encontrados por Tanasichuk \& Makay (1989) para a Perca fluviatilis Linnaeus, 1758.

A estratégia alimentar descrita para o matrinxã confirma a grande potencialidade desta espécie para a piscicultura, devido a seu hábito alimentar onívoro, alimentando-se tanto na superfície como no fundo dos corpos de água (Menezes, 1969; Cyrino et al., 1986; Zaniboni-Filho, 1985). Por outro lado, Castagnoli (1979) afirmou que o aproveitamento ótimo de qualquer tipo de alimento não depende somente do valor nutricional deste, mas também da capacidade de assimilação do animal.

Desta forma nossos dados indicam que o matrinxã, $B$. cephalus é um peixe onívoro, bem adaptado aos sistemas de áreas alagáveis, que aproveita eficientemente o alimento disponivel, desenvolvendo uma estratégia alimentar no sentido de 
acumular reservas durante a época de maior oferta alimentar para sobreviver nos períodos de escassez de alimento.

A maior disponibilidade de proteína na dieta do matrinxã é no periodo da seca e está relacionada ao consumo de alimento de origem animal. Entretanto a maior fonte energética na sua alimentação é fornecida de frutos e sementes no período da enchente e cheia. Insetos constituem-se também como um item importante na dieta do matrinxã neste período.

\section{AGRADECIMENTOS}

Os autores agradecem ao $\mathrm{CNPq}$ pelo suporte financeiro, e pela bolsa concedida.

\section{Bibliografia citada}

A.O.A.C. 1995. Association of Official Analytical Chemists. Official Methods of Analysis. 17ª.ed. $1141 \mathrm{p}$.

Borges, G. A. 1986. Ecologia de três especies do gênero Brycon (Muller-Troschel, 1844) (Pisces-Characidae) no rio Negro Amazonas, com ênfase na caracterização taxonômica e alimentação. Dissertação de Mestrado, Instituto Nacional de Pesquisas da Amazonia/Fundação Universidade do Amazonas. 150p.

Cánepa, J. 1982. Estudio Bioecológico del "sabalo cola roja" Brycon ervthropterum en el sistema de lagunas Supay y Aledaños, Jenaro Herrera. Requena. Tesis para obtener el título de ingeniero pesquero-oceanografo-hidrobiológico. UNFV1, Programa Académico de Oceanografia y Pesqueria. Lima, Perú. $114 \mathrm{p}$.

Castagnolli, N. 1979. Fundamentos de Nutrição de Peixes. Livroceres, Piracicaba, Brasil. 108p.
Cyrino, J.E.P.; Castagnolli, N.; Pereira-Filho, M. 1986. Digestibilidade da proteina de origem animal e vegetal pelo matrinxã, Brycon cephalus (Gunther, 1869) (Euteleostei, Characiformes, Characidae). In: Anais do Simpósio Brasileiro de Aqüicultura. Cuiabá, Mato Grosso. p 49-62.

Goulding, M. 1980. The fish and the forest: explorations in Amazoniam natural history. University of California Press, Los Angeles, USA. 280p.

Howes, G.1982. Review of the genus $\underline{B r y c o n}$ (Teleostei: Characoidei), Bulletin of the British Museum of Natural History (Zoology), 43(1):1-47.

Junk, W.J. 1985. Temporary fat storage, an adaptation of some fish species to the water fluctuations and related enviroment changes of the Amazon river. Amazoniana, 9(3):315-351.

Knoppel, H.A. 1970. Food of Central Amazonian Fish. Contribution to the nutrient of Amazonian rain-forest-streams. Amazoniana, 2(3):257-351.

Menezes, N.A. 1969. The food of Brycon and three closely related genera of the tribe. Acestrorhynchini. Papeis Avulsos de Zoologia de São Paulo, 22:217-223.

Revilla-Cardenas, J. 1981. Aspectos florísticos e fitossociológicos da floresta inundada (Igapó) praia Grande, rio Negro, Amazonas, Brasil. Dissertação de Mestrado. Instituto Nacional de Pesquisas da Amazonia/Fundação Universidade do Amazonas, Manaus, AM. 129p.

Roubach, R. 1991. Uso de frutos e sementes de floresta inundáveis na alimentação de Colossoma macropomum (CUVIER, 1818) (PISCES, CHARACIDAE). Dissertação de Mestrado. Instituto Nacional de Pesquisas da Amazonia/ Fundação Universidade do Amazonas. Manaus, AM. 79p.

Santos, G.M. 1990. Pesca e ecologia dos peixes de Rondônia. Tese de Doutorado. Instituto Nacional de Pesquisas da Amazonia/Fundação Universidade do Amazonas. Manaus, AM. 213p. 
Silva, J.A.M. 1997. Nutrientes, energia e digestibilidade aparente de frutos $e$ sementes consumidos pelo tambaqui (Colossoma macropomum (CUVIER, 1818)) nas florestas inundáveis da Amazônia central. Tese de doutorado. Instituto Nacional de Pesquisas da Amazonia/Fundação Universidade do Amazonas, Manaus, AM. 142p.

Tanasichuk , R.W.; Makay, W.C. 1989. Quantitative and qualitative characteristics of somatic and gonadal growth of yellow perch Perca flavescens, from lac Ste Anne, Alberta, Can. Journal of Aquatic Science, 46:989-994.

Villacorta-Correa, M.A. 1987, Crescimento do matrinxã, Brycon cephalus (Günther, 1869) (Teleostei, Characidae) no baixo rio Negro, seus afluentes, e no baixo rio Solimões. Dissertação de mestrado. Instituto Nacional de Pesquisas da Amazonia/Fundação Universidade do Amazonas. Manaus, AM. 123p.

Wootton, R. J. 1979. Energy cost of egg prodution and enviromental determinants of fecundity in teleost fishes. Symposium Zoological Society of London, 44:133159.

Zamal, H.; Ollevier, F. 1995. Effect of feeding and lack of food on the growth, gross biochemical and fatty acid composition of juvenile catfish. Journal of Fish Biology, 46:404-414.

Zaniboni-Filho, E, 1985. Biologia $d a$ reproduçâo do matrinxã, Brycon cephalus (Gunther, 1869) (Teleostei: Characidae).
Dissertação Mestrado. Instituto Nacional de Pesquisas da Amazonia/Fundação Universidade do Amazonas. Manaus, AM. $134 \mathrm{p}$.

Zaniboni-Filho, E.; Resende, E.K., E. 1988. Anatomia de gônadas, escalas de maturidade e tipo de desova do matrinxã, Brycon cephalus (Günther, 1869) (Teleostei: Characidae). Revista Brasileira de Biologia, 48(4):833-844. 